\title{
Public e-procurement impacts in small- and medium-enterprises
}

\section{Teresa Fernandes* and Vítor Vieira}

Faculty of Economics,

University of Porto,

Rua Dr. Roberto Frias, s/n, 4200-464 Porto, Portugal

Email: tfernandes@fep.up.pt

Email: vieiravmg@gmail.com

*Corresponding author

\begin{abstract}
The European Union (EU) created directives to regulate the moving to full Public e-Procurement (Pe-P) for all public purchases by 2016. Despite the undisputable benefits, member states are lagging behind on this paradigm shift. Also Pe-P's scholarly evaluation and theoretical knowledge behind it are still very limited. This paper makes a contribution to the literature gap related to Pe-P's impacts providing preliminary evidence of its adoption in Portugal. Following a case-based approach involving interviews with managers from the Portuguese construction sector, our study aims to understand Pe-P's implementation benefits and barriers in small- and medium-enterprises (SMEs). Results provide relevant information regarding factors affecting Pe-P's adoption forecasting implications for private firms, platform providers and policy makers in the 2016 full moving to Pe-P's throughout the EU.
\end{abstract}

Keywords: e-procurement; public e-procurement; P e-P; small- and medium-enterprise; SME; adoption; benefits; barriers.

Reference to this paper should be made as follows: Fernandes, T. and Vieira, V. (2015) 'Public e-procurement impacts in small- and medium-enterprises', Int. J. Procurement Management, Vol. 8, No. 5, pp.587-607.

Biographical notes: Teresa Fernandes is the Course Director for MSc in Services Management and Assistant Professor of Marketing and Services at the Faculty of Economics, University of Porto, Portugal. She holds a PhD in Business Management, Faculty of Economics, University of Porto, Portugal. Her main research focus is on consumer relationships and services marketing. She has published in the Journal of Marketing Management, Journal of Financial Services Marketing, Journal of Relationship Marketing and Journal of Strategic Marketing.

Vítor Vieira is a London-based Engagement Manager at Clarabridge's EMEA Professional Services and a former Consultant/Project Manager at VORTAL, the leading e-procurement SaaS provider in Portugal. He has extensive and in-depth professional experience in the areas of e-sourcing, e-procurement, software implementation, project management and key account management gained from his work with services, construction, retail and energy sectors. He holds an MSc in Services Management, Faculty of Economics, University of Porto, Portugal. 
This paper is a revised and expanded version of a paper entitled 'Public e-procurement perceived impacts: the case of Northern Portuguese SMEs' presented at INBAM 2013 (3rd Conference of the International Network of Business and Management Journals), Lisbon, Portugal, 17-19 June 2013.

\section{Introduction}

The last decade has seen many governance functions migrate to the internet (Thai, 2001). The development of information and communication technologies (ICT) opened a wide range of opportunities for improving processes within and between organisations. Following the lessons of the private sector, also public institutions turn to ICT on the quest for efficiency and effectiveness. A number of public sector agencies worldwide have identified e-procurement as a priority for the e-government agenda and public procurement is being perceived as a major function of government. However, the scholarly evaluation of Public e-Procurement (P e-P) initiatives is very limited (Vaidya et al., 2006; McCue and Roman, 2012). The reason for this might be that e-procurement implementation initiatives in the public sector are still in their early stages (Basheka et al, 2012; Tonkin, 2003). However, because e-procurement is currently one of the key topics in the e-government arena, many organisations need guidance about proceeding with this new technology, system and processes. Namely, small- and medium-enterprises (SMEs), though representing a crucial role in employment and the whole economy (Doern, 2009), may find it difficult to become suppliers in public procurement (Fee et al., 2002; Clark and Moutray, 2004; Zheng et al., 2006). However, current knowledge involving small businesses and public procurement is still limited (Karjalainen and Kemppainen, 2008).

Following a case-based approach, our study aims to bridge this literature gap by exploring the benefits and barriers of $\mathrm{P}$ e-P in Portuguese SMEs, involving interviews with procurement managers of a convenience sample of construction companies. The case was chosen given his groundbreaking potential, following the Portuguese full adoption of $\mathrm{P}$ e-P on all public contracts. Portugal was the first country with mandatory adoption of $\mathrm{P}$ e-P in the EU, making it an interesting case study (Costa et al., 2013). Within the EU, Portugal leads the ranking of $\mathrm{P}$ e-P penetration (100\%), despite a $5 \%$ average compliance rate among member states. Furthermore, SMEs represent $99 \%$ of all registered businesses in the country, and are the backbone of Portuguese economy. Also, most studies on procurement focused on large companies (Tatsis et al., 2006) and research on SMEs acting as suppliers is still limited (Karjalainen and Kemppainen, 2008). Namely, while governments increasingly adopt e-procurement, the impact of IT usage in SMEs' involvement in the public sector has not been fully studied (Zheng et al., 2006). Moreover, though there are some studies dedicated to SMEs and procurement in countries like the USA, Ireland, Finland, Australia or Malaysia (e.g., Fee et al., 2002; Clark and Moutray, 2004; Hawking et al., 2004; Karjalainen and Kemppainen, 2008; Eei et al., 2012), to the best of our knowledge till date there is no structured research about the subject done in Portugal. Finally, although e-procurement adoption has been studied in specific industries, such as health, hospitality, manufacturing and technology-based (Sigala, 2006; Tatsis et al., 2006; George et al., 2011), research focusing the construction sector has been minimal (e.g., Eadie et al., 2012). In the following sections, we discuss the background, requirements, and impacts of e-procurement implementation in the 
public sector from the suppliers' point of view. The main overall objectives of the paper are to gain a better understanding of $\mathrm{P}$ e-P issues in the public sector, namely from SMEs' point of view, and to stimulate debate on the e-procurement impacts.

\section{Literature review}

\subsection{E-procurement definition and benefits}

For companies to remain competitive in the market, they must reduce the costs of their components, materials and services by sourcing from least-cost suppliers. One method to achieve it is through open bidding via the internet (Yu et al., 2008). This migration of procurement functions to internet is known as e-procurement.

E-procurement has been defined by many authors (e.g., Davila et al., 2003; Yen and Ng, 2003; Hawking et al., 2004; Makinen et al., 2011). Tatsis et al. (2006) present several definitions. Scholars have defined e-procurement as an "internet-based purchasing system that offers electronic purchase, ordering processing and enhanced administrative functions to buyers, suppliers" (Panayiotou et al., 2004) or "the sourcing of goods and services via electronic means, usually through the internet" (Schoenherr and Tummala, 2007). In basic terms, e-procurement can be defined as "using Internet technology in the purchasing process" (De Boer et al., 2002). Though sometimes used interchangeably with the term 'e-purchasing', the latter has a much narrower scope. While e-purchasing is simply a transaction conducted electronically, e-procurement can be viewed more broadly as an end-to-end solution that integrates and streamlines many procurement processes throughout the organisation (Vaidya et al., 2006). E-procurement is an 'umbrella term' [Fleming et al., (2010), p.232] that encompasses several elements, including electronic ordering, internet bidding, purchasing cards, reverse auctions, and integrated automatic procurement systems (Moon, 2005; George et al., 2011). E-procurement has been recently receiving much attention from businesses, industries and governments as it is reportedly become a powerful tool to improve effectiveness and efficiencies as well as service quality of its adopters (Basheka et al., 2012; Eei et al., 2012) and its application is nowadays inevitable in both manufacturing and services, not also in the private but also in the public sector (Gunasekaran and Ngai, 2008; Schiele, 2007). Companies have moved to e-procurement platforms, where transactions are done efficiently and in a fast pace (Makinen et al., 2011). The literature underlines numerous benefits of migration of procurement functions to internet. This new process is expected to benefit all facets of procurement, including selecting, bidding, payment and inventory processes (Basheka et al., 2012). Operational and cost efficiency are perceived as the primary advantage of e-procurement (De Boer et al., 2002; Brandon-Jones and Carey, 2011). Web-based purchasing is also believed to offer the capability to develop effective long-term strategic approaches, improve process and budgetary controls, and reduce transaction costs, hence leading to more efficient supply markets (Croom and Johnston, 2003) and increased competitive advantage to the firm (Makinen et al., 2011). Furthermore, e-procurement offers buyers and sellers a new form of communication (Karthik and Kumar, 2013) and facilitates the documentation of the bidding process, enhancing transparency and accountability of operations (Croom, 2000). Increased internal customer satisfaction is also a benefit associated with e-procurement (Croom and Johnston, 2003). Scholars assert that implementation of e-procurement initiatives could 
improve the professionalism and outside perceptions of procurement specialists (Croom and Johnston, 2003). Finally, e-procurement applications have positive impact on employees' satisfaction, job formality and work relationships (Aslani et al., 2008).

\subsection{E-procurement in the public sector}

The quest to improve service delivery is becoming an important agenda for most governments (Kaliannan et al., 2009, Vaidya and Hyde, 2011; Basheka and Sabiiti, 2011) and e-procurement has been introduced as a key strategic tool in increasing nations' competitiveness (Basheka et al., 2012) and as a way to achieve better, more cost effective procurement systems, as well as greater transparency and accountability (Karthik and Kumar, 2013).

Moon (2005) defines P e-P as a comprehensive process in which governments use IT systems to establish agreements for the acquisition of products or services (contracting) or to purchase products or services in exchange for payment (purchasing). Adebiyi et al. (2010) define electronic government procurement (e-GP) as online applications of information technology and infrastructure to the management, processing, evaluation and reporting of government procurement. According to Vaidya (2007), P e-P has been defined as "the use of any internet-based inter-organisational information systems that automates and integrates any parts of procurement process in order to improve efficiency, transparency, and accountability in the wider public sector".

Improving procurement is a priority within the $\mathrm{EU}$, since it represents the starting point for the control of public deficits and good economic development. To this end, the budget allocated to $\mathrm{P}$ e-P has become critical since the benefits of e-procurement in the public sector translate into effects that impact directly and dramatically the competitiveness and profitability of organisations (Bechtel and Jayaram, 1997; Olsen and Ellram, 1997, LaLonde, 1998; Roberts, 2001). Thus, the e-procurement is an important tool for decreasing acquisition costs and increasing process efficiency (Ho et al., 2006) from the buyer and the supplier point of view. Pe-P's flow is divided into two stages: preaward and post-award (Figure 1).

Figure 1 Pe-P's flow (see online version for colours)

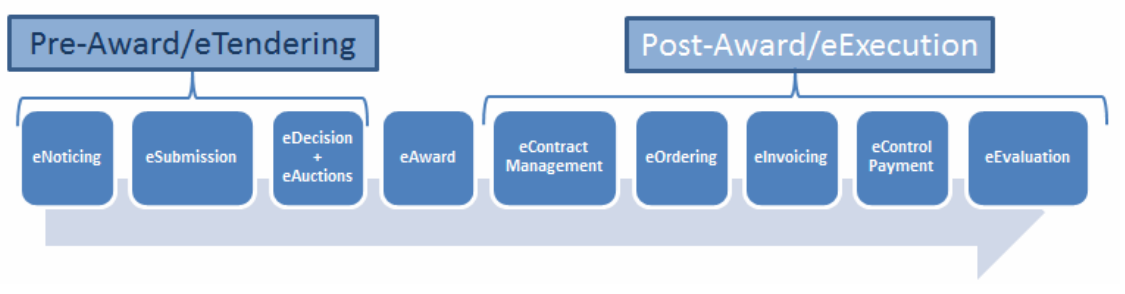

Source: Tavares (2010)

According to Tavares (2010), the implementation of these two phases in the EU is not homogeneous, being e-noticing the most widespread. Also the phases that comprise the pre-award period are critical to better apply principles of strategic procurement since they include tasks related to planning, environmental and social responsibility and certification and qualification of competitors. Post-award stages comprise focus on operational issues 
that may also contribute to reducing costs and time due to better management and contractual control.

Worldwide e-procurement implementation initiatives have been undertaken in the public sector on a large scale (Henriksen and Mahnke, 2005; Somasundaram and Damsgaard, 2005; Vaidya, 2007; Mota and Filho, 2011) as government procurement represents $18.42 \%$ of the world GDP. E-procurement is used by government agencies and other actors of procurement community in conducting activities of the government procurement process cycle (GPPC) for the acquisition of goods, works, and consultancy services with enhanced efficiency in procurement management. Namely within the EU there has been significant progress in the implementation along certain e-procurement dimensions (Varney, 2011). All EU members use e-notices for at least $85 \%$ of contracts, with many states employing e-notification more than $95 \%$ of the time. Public procurement represents 17\% of EU's GDP (European Commission, 2011a, 2011b) and between 2006 and 2008 SME have won $60 \%$ of the contracts covered by EU directives, representing $34 \%$ of the total value of contracts awarded in that period.

In order to ensure that EU suppliers are given an equal opportunity to contract with public bodies, the EU has adopted two new directives which include e-auctions, and advanced e-signatures; embedding sustainability, environmental considerations, and social responsibility into procurement practice.

These efforts, however, have been associated with varying levels of success (Bof and Previtali, 2007; Basheka et al., 2012). In some cases the implementation of e-procurement has led to the expected outcomes, while in other poorly designed adoption processes caused high failure and financial waste (Somasundaram and Damsgaard, 2005). Current studies (e.g., Davila et al., 2003, Lancioni et al., 2003, Min and Galle, 2003) suggest that growth rates have been under expectations. The implementation of e-procurement has not been as easy as some of the solution providers have suggested, nor has it necessarily brought the anticipated savings (Costa et al., 2013). For instance, in 2005 Declaration of Manchester, the EU targeted that by 2010 at least $50 \%$ of public procurement were to be made electronically, but currently only $5 \%$ of total public procurement in average are conducted electronically, e.g., 5\% in England, 4\% in Italy or $30 \%$ in Scotland (Tavares, 2010). Furthermore, engaging suppliers in the process especially smaller organisations - is also proving to be difficult given the level of investment expected in terms of providing catalogue information to buyers, and marketplaces using different technologies, platforms and business languages (Karjalainen and Kemppainen, 2008; Office of Government Commerce, 2008). Adoption barriers could stem from infrastructure, strategy, people or culture (Karthik and Kumar, 2013).

Such success and failure stories imply that there is a need for a much better understanding of e-Procurement use in the public sector (Tonkin, 2003). In the following section, we will discuss $\mathrm{P}$ e-P impacts to governments as well as adoption facilitators and inhibitors to suppliers.

\subsection{P e-P impacts, adoption drivers and inhibitors}

Public procurement is at the forefront of most reform efforts, given that it plays a significant role in promoting accountability and transparency (McCue and Roman, 2012). An organisation will procure goods and services electronically if there are enough benefits that might be gained from e-procurement (Gupta et al., 2011). Ronchi et al. (2010) found five areas of benefit including greater transparency, control, 
decentralisation, maverick buying reduction, and supply based rationalisation. Wen and Wei (2007) found the benefits of P e-P to be greater efficiency, lower cost, and time saved per transaction, as well as greater flexibility, enhanced accessibility of procurement information, faster communication, quick time response and improved procurement quality. Proponents of e-procurement argue that it helps governments to save money and provides a more accountable, effective and faster way to manage procurement, by streamlining government acquisition processes and integrating technology infrastructures (Azadegan and Ashenbaum, 2009). Neef (2001) suggested that the potential benefits of eprocurement are the following:

1 lowered transaction costs

2 faster ordering

3 wider vendor choices

4 standardised, more efficient procurement processes

5 greater control over procurement spending (less maverick buying) and better employee compliance

6 more accessible internet alternatives for buyers

7 less paperwork and fewer repetitious administrative procedures

8 reengineered procurement workflows.

Fleming et al. (2010) present reduced administrative costs, improved business processes, increased buying power and value provided to suppliers as value-added opportunities of e-procurement. Davila et al. (2003) indicate that e-procurement technologies will become an important part of supply chain management and that the rate of adoption will accelerate as the adopters share their experiences of success factors and perceptions of low risk. Also, according to Karthik and Kumar (2013), e-procurement can be seen as a means to significantly reduce transaction costs and time spent on negotiation. Similarly, Barua et al. (2001) identified e-procurement as the element of e-business most contributory to the operational excellence of large corporations, while Gupta and Narain (2012) present it as an opportunity for small businesses that wish to compete beyond their comfort zone.

Thus, Pe-P's implementation produces significant impacts on the suppliers and service providers of public entities. Namely, ICT tools are important to help SME increase their effectiveness and efficiency by improving business communications and process, reduce cost, explore new business opportunities, increase transparency in contracts and overall competitiveness. The inclusion of e-Procurement allows suppliers, especially SME, to place their invitations to tender by these means only, increasing transparency and competitiveness (Kierkegaard, 2006).

\subsubsection{P e-P adoption drivers}

$\mathrm{P}$ e-P provides a wide range of important innovations that can drive adoption (Aslani et al., 2008, Aberdeen Group, 2009, European Commission, 2004) transforming the purchasing process from an operational into a strategic activity (Gupta and Narain, 2012). Major e-procurement benefits include: 
1 Transaction costs reduction: cost-related benefits have been mentioned by a number of authors (e.g., Croom and Johnston, 2003; Presutti, 2003; Yen and Ng, 2003; Hawking et al., 2004; Puschmann and Alt, 2005; Tatsis et al., 2006; Croom and Brandon-Jones, 2007; McConnell, 2009; Karthik and Kumar, 2013) and include reduced price, administration and inventory costs, and inaccuracies (Smart and Harrison, 2003).

2 Contracting time reduction: in this case the tout electronique advent allows significant time reductions in all phases of the public procurement procedures (Tatsis et al., 2006). According to Tavares (2010) between the old and new process, a $40 \%$ reduction of the contracting time can verified. This impacts public and state suppliers.

3 Increased transparency: the introduction of technology allows the sharing of information on all steps of the process, to competitors and between competitors and the acquiring public entity, automatically and instantly. This results in reduced complexity and improves transparency (Croom and Brandon-Jones, 2007; Johnson, 2011).

4 Increased competitiveness: due to the procedures publication via electronic platform, a larger number of competitors bid in the procedures and increase competitiveness (Johnson, 2011), resulting in increased productivity and market access (Rankin et al., 2006).

5 Tenders Increased Value: foreseeing the favourable previous impacts, the propensity for selecting the most economically advantageous proposal increases for the contracting authority and suppliers elaborate more informed and competent proposals.

6 Higher information systems integration: as procurement activities are centralised, different offices/departments can access the same information when required (Fleming et al., 2010), an advantage over the much more slower process of having to post documentation between offices/departments (Arasa and Achuora, 2012), thus improving communication and information flow (Croom, 2000).

In addition to these impacts, other positive drivers relate to the commercial ubiquity provided to organisations. Suppliers gain a superior geographical range along with higher commercial competitiveness and existing business relationships consolidation (Ciciriello, 2010). Therefore, $\mathrm{P}$ e-P provides superior access to business opportunities without the constraint of the supplier geographical location, increasing exposure with minimal sales effort (Fleming et al., 2010). Also centralised functions do not have departmental or time barriers (Arasa and Achuora, 2012). Moreover, sellers gain the ability to receive bid notices without ever meeting the buyers (Fleming et al., 2010). Finally, another benefit which arises from Pe-P's adoption connected to higher qualified employee motivation and retention due to the adoption of new technologies in everyday work (McConnell, 2009). 


\subsubsection{P e-P adoption inhibitors}

Apart from positive impacts which facilitate Pe-P's adoption, a range of authors (e.g., MacManus, 2002; Zheng et al., 2004; Puschmann and Alt, 2005; Tatsis et al., 2006; McConnell, 2009) has identified a number of general inhibitors, which include:

1 technology related inhibitors: obstacles related to concerns about the security of the information traded, the absence of a single P e-P solution, the lack of interoperability between systems and low uniformity in procurement procedures

2 process related inhibitors: these are related to low propensity for organisations to conduct processes reengineering, the still low rate of technological solutions adoption by suppliers and the e-procurement solutions cost

3 culture and people related inhibitors: these highlight the workforce deficit in specific procurement qualifications, resistance to change and absence of adequate organisational culture to encourage technological vanguard

4 legal compliance level and adoption inhibitors: in this case, there have been identified public policies negative impact and legal constraints that arise due to, for example, the interpretation of the new legal framework.

Alongside with these general inhibitors, a number of sector specific constraints have also been identified. Panayiotou et al. (2004) studied inhibitors in the Greek public sector and identified the complexity of goods and services, the need for transparency and regulatory constraints. Sigala (2006), in a study about foodservice operators in Greece, found out that lack of e-procurement knowledge, skills, trust and risk perception were the main inhibitors of e-procurement adoption. Hawking et al. (2004) researched SME in Australia and found that one of the main inhibitors was the absence of a single e-procurement solution. In a similar study, Eei et al. (2012) identified internal and external barriers to the implementation of e-procurement in Malaysian SME. Karjalainen and Kemppainen (2008) used data from Finnish SMEs to conclude that availability of resources, company size and e-systems explained the level of SEM involvement. Also Zheng et al. (2004) refer specific inhibitors to SME: lesser resources, smaller infrastructures and company size are the more important constraints in adopting P e-P. Tavares (2010) considers that the lack of know-how and support in the use of these platforms represents one of the biggest inhibitors to $\mathrm{P}$ e-P adoption, namely in SME.

\subsection{The importance of electronic platforms}

E-procurement means that all purchasing is done through electronic channels. Forms of electronic communication such as e-sourcing, e-auction or e-noticing become possible. Tenders are run electronically so that the maximum number of suppliers can compete, making it easier to identify contract opportunities and to supply their goods and services (Kierkegaard, 2006). Replacing the traditional methods of paper based procurement (which account for the use of colossal amounts of paper transactions, deliveries by mail and formal sessions to open sealed envelopes) with the introduction of ICT (using only in electronic format documents, processes and communication-based portals or platforms) is a giant step towards the knowledge society which requires a broad and complex process of change (Tavares, 2010). A determinant player emerges to support the advent: technology partners, which hold e-Procurement solutions and electronic markets. Tavares 
2010), refers to these players as 'technological enablers' which provide the necessary technological support of the paradigm shift.

The electronic process proves to be simpler, faster, transparent, auditable, dematerialised, modern and democratically available to any citizen or company that has internet access and a computer (Tavares, 2010). In general, the adoption of electronic platforms allows for efficient and effective management of all operations related to P e-P phases for the public and competing suppliers, supporting the easy comparability of attributes and criteria of the tenderers without paper handling, the communication between the contracting authority and competitors and the realisation of electronic auctions which are a powerful tool for competitiveness. In conclusion, electronic platforms function as facilitators and support Pe-P's advent, allowing a higher level of procedures traceability and audit, democratised access to information and public markets business opportunities access in a dematerialised form. These ultimately lead to safe, confidential and transparent transactional means.

\section{The research}

Given the number of successes and failures reported in literature, our research set out empirically to examine P e-P implementation and impacts. Namely, this exploratory study aims to assess Pe-P's perceived impacts on Portuguese SMEs construction suppliers, assessing their perceptions, inhibitions and motivations. The case was chosen given his groundbreaking potential. On one hand, Portugal presents itself as a case of success in e-gov implementation. On the other hand, the role of SMEs in economic growth, job creation regional and local, and social cohesion was recognised by the Bologna Charter on SME Policies (OECD, 2000). In the case of Portugal, SMEs represent $99 \%$ of all registered businesses, and thus are the backbone of the whole economy. About 114,000 of these companies were located in northern Portugal and 50,000 were linked to the construction sector, employing approximately 320,000 people. It is important to realise that only $40 \%$ of these companies turnover referred to exports, which means that the Portuguese market is paramount to the industry survival (National Statistics Institute, 2011).

\subsection{Pe-P's adoption in Portugal}

In Portugal, EU's Directives 2004/17/EC and 2004/18/EC that regulated the early adoption of $\mathrm{P}$ e-P have been transposed into the national legal framework. These induce widespread and profound changes in public procurement's law and also in an entire industry, culture, practices, business models and technology organisations in the public sector (more than 14,000 organisations) and the state suppliers (Tavares, 2010). This mandatory adoption of electronic means, made Portugal the pioneer between EU's 27 member states, in contrast with the adoption rates of electronic means in other member states such as England (5\%), Scotland (30\%) or Italy (4\% for goods and services; $0 \%$ for works).

Following the early 2004 EU's directives, in 2009 Portugal turned mandatory the full adoption of $\mathrm{P}$ e-P to all public contracts. Within the EU, Portugal leads the ranking of $\mathrm{P}$ e-P penetration $(100 \%)$, despite a $5 \%$ average compliance rate among member states (Tavares, 2010). 


\subsection{Research methodology}

We have decided to structure our analysis according to a research framework (Figure 2) constructed on the foundations of e-procurement literature. This model helped us to develop research questions and delineate the phenomena with which the study would be interested. Overall, while analysing SMEs Portuguese construction suppliers, our aim is to assess:

1 the perceived positive impacts on business competitiveness and contribution to people's integration in the digital society induced by $\mathrm{P}$ e-P implementation

2 positive economic and financial impacts induced by the new contracting system, here including the level of financial benefits that the new system provided

3 perceived impacts on marketing models and commercial policies as well as changes on procedures transparency provided by the platforms introduction Public Procurement

4 the investment required for the new system compliance regarding technological improvements, organisational adjustments and changes as well as the training effort

5 the difficulties in Pe-P's implementation

6 improvement propositions in electronic platforms and systems connected to $\mathrm{P}$ e-P

7 evaluation of the private supply chain modernisation as a result of technology based P e-P.

Figure 2 Research framework (see online version for colours)

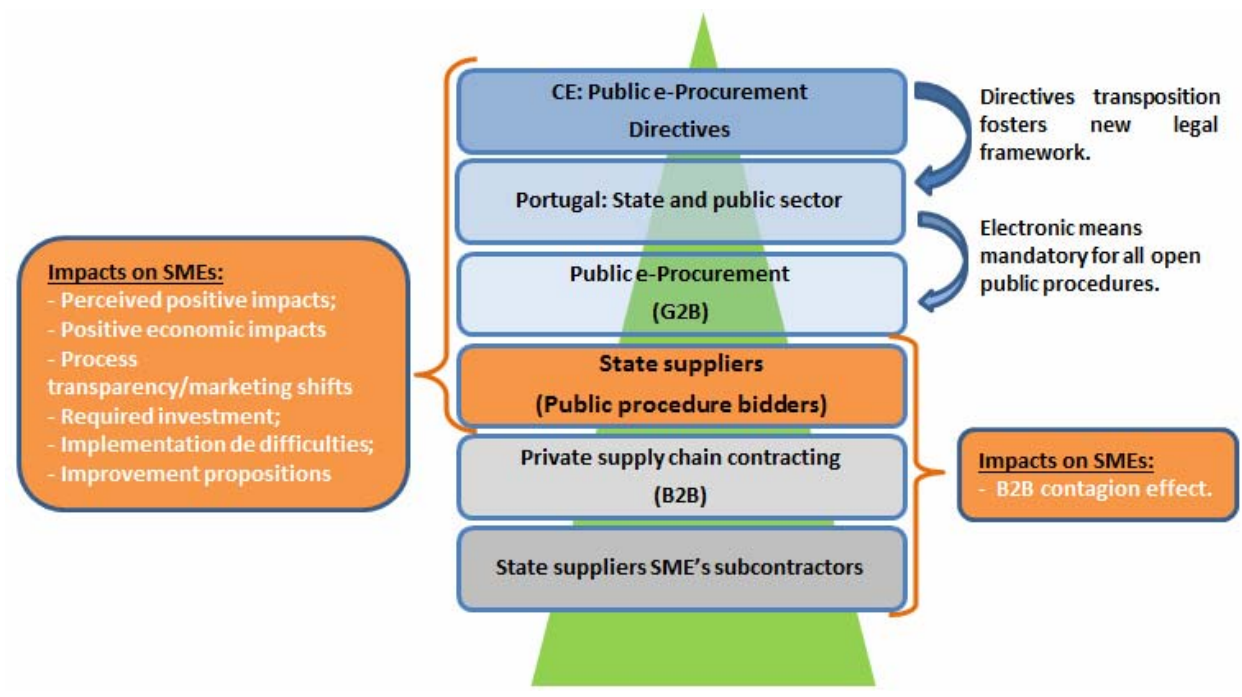

In order to infer these perceived impacts, we used a case-based approach (Yin, 2014) with multiple units of analysis (Dubois and Araujo, 2007). Yin (2014) recommends the case study approach when research questions require an extensive and 'in-depth' description of phenomenon. Given the nature of e-procurement adoption in SMEs, it was critical to conduct an exploratory case study research as the main data collection vehicle. 
The case consists of a group of SMEs in the Portuguese construction sector. This sector is known to face a series of problems in relation to achieving key project objectives of timely delivery, within budget, and attainment of quality standards (Oyegoke et al., 2010) and, thus, may highly benefit from e-procurement implementation. Nine SMEs have been included in this study, representing e-procurement adopters SME significantly impacted by Pe-P's advent (Table 1). Data was collected through multiple sources of evidence (Yin, 2014), including company-specific documentation, introductory sessions in the case companies and semi-structured interviews. The interviewees were selected on the basis of their position in the case companies, and represented strategic and operational levels of purchasing. Namely: four were commercial directors, three worked in the commercial department and one was a commercial technical specialist. As these are key employees in their respective organisations, it was anticipated that the information collected would be the most reliable and assertive possible. The use of multiple respondents also allowed us to capture a variety of perceptions surrounding a complex phenomenon (Dubois and Araujo, 2007). Questions about perceived impacts of P e-P implementation, investments required, evaluation of electronic platforms and supply chain modernisation were asked and data was subject to qualitative content analysis. Our research design used both semi-structured and open questions, thereby allowing respondents to discuss at length their experiences, perceptions and reflections of a range of electronic procurement implementation projects. In average, interviews lasted one hour and were taped and transcribed verbatim. All interviews were taped and transcribed verbatim. Coding of all interviews was undertaken and then cross-compared for final coding and identification of core themes. The review and comparison of themes represented an informal 'content analysis' that allowed for the discovery of distinct patterns of content regarding e-procurement (Carson et al., 2001). This information, coupled with a review of the extant literature, were the bases of data analysis. In the next section of the paper we present the key findings relating to the experiences of our sample respondents from their involvement with e-procurement implementation.

Table 1 SMEs sample description

\begin{tabular}{lcc}
\hline SME & Business volume $(M €)$ & Number of workers \\
\hline 1 & 77.8 & 485 \\
2 & 142.1 & 128 \\
3 & 28.0 & 100 \\
4 & 45.5 & 276 \\
5 & 120.0 & 419 \\
6 & 16.5 & 110 \\
7 & 8.3 & 60 \\
8 & 23.0 & 150 \\
9 & 7.0 & 120 \\
\hline
\end{tabular}

\subsection{Research key findings}

In this section we present the summary findings of our analysis, according to seven parameters defined on the research framework. These sections relate directly to the seven themes previously identified, in order to provide a clear link between our study findings 
and the existing literature. Excerpts from conversations with SME's executives are also provided in order to capture snapshots of the e-procurement adoption process dynamics.

\subsubsection{Perceived positive impacts on business competitiveness and staff digital integration}

It is fairly unanimous recognised by the interviewees that the main $\mathrm{P}$ e-P positive impacts relate to the full process dematerialisation, the increased speed to information access and competitiveness, the larger geographical range and a more efficient and effective competitor analysis.

Processes dematerialisation due to technology introduction, account for rapid information processing, processes adhocracy and dramatic transaction costs reduction:
"One of the main advantages is the dematerialization, no doubt. The fact that we no longer have paper processes is one of the first advantages. The second advantage is that we can, in a very short period of time, get involved in a larger number of tenders, which in the previous paper based process was unthinkable (as we needed to travel to many places to get the tender documentation, return, work on it and then travel again to deliver the paper bid." (SME5)

In fact, the geographic amplitude enhancement that platforms provide to companies enables the selection of contractors that are geographically dispersed throughout the country, with no need for physical travel for bidding. Hence, public procurement's computerisation enables SME to broaden the range of potential customers and business opportunities, regardless of their geographic location and, this geographical reach increase, implies no additional effort resource as the previous paper based Public Procurement method. Once centralised in a software application, it becomes equally accessible to any of these companies to compete for a contract in the North of Portugal (regarded as the priority area of the respondents) or in the South of Portugal given the ubiquity that computerised systems provide. Finally, it is mentioned by respondents that there is increased competitiveness and improvements in their companies' market positioning which provides a strategic advantage, given the possibility of detailed and deeper competition study and analysis (because all bidders bids and additional files are available on the platform after the public contractor makes their disclosure, in the analysis stage of the procedure). This analysis is carried out freely and expeditiously and allows the development of more informed strategically assertive proposals afterwards contributing to the strategic positioning of SME in future tenders:

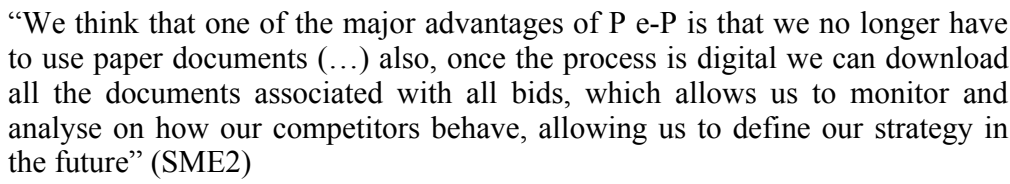

According to the respondents, $\mathrm{P}$ e-P also contributes to people's integration in the digital society. The answers often focused on the fact that the use of electronic platforms, helped creating a digital and stimulating modern environment as well as contributing to the employees motivation and self-esteem, which is consistent with investigations of McConnell (2009) about the additional motivation and retention of staff by introducing technologies in everyday life: 


\begin{abstract}
"Along these years, with the introduction of platforms in our day to day, our people discuss and question all aspects related to this advent, accesses, updates, new information from our customer, messages, digital certificates etc. They look to understand everything because they want to be at the forefront, want to know what's new. I firmly believe they even feel their work and themselves are more important to the organization because they get much more involved in tender, bids, connect with our customers" (SME7)
\end{abstract}

\title{
3.3.2 Positive economic and financial impacts induced by the new contracting system
}

It was noted that one of Pe-P's major benefits is transaction costs reduction, namely, paper and travel costs. Technology replaces the all the travel necessary to bid as well as paper processing. Given the digital processing of all the information related to public contracts, the costs with waste paper as well as man-hours assigned for organising the administrative work processes is dramatically reduced. Similarly, the cost of travel and staff allocated to logistical tasks also tends to be residual due to the introduction of technology in the process:

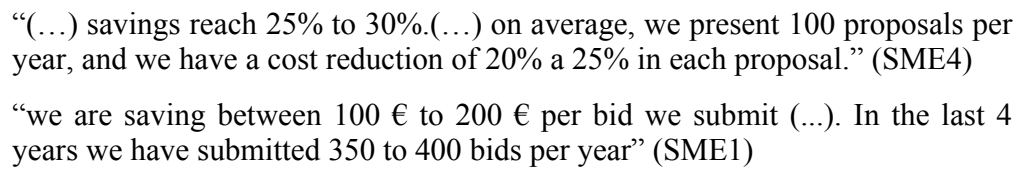

It was further questioned about the number of proposals submitted annually to evaluate, roughly, the values saved annually with the new system. However, in this field there is no consensus regarding the approximate number of proposals presented by each commercial department. However, a few intervals were suggested and we could estimate a $50 \%$ cost reduction per bid elaborated which, in some cases accounts for savings of around $€ 300$ per bid (which multiplied by the yearly hundreds of bids submitted may result in an annual economic benefit that can exceed tens of thousands of Euros per SME surveyed). It is, however, more research needed to accurately measure these values.

\subsubsection{Perceived impacts on marketing models and commercial policies}

Despite being acknowledged the platforms' potential to break with old paradigms, there hasn't been unanimity that the new system caused significant changes in the interviewees firms' market approach. Responses obtained suggest that platforms provide the opportunity to fostering new markets approach due to access to diversified business opportunities. However, only in a few cases this potential was translated into the development of new markets. In these cases, where $\mathrm{P}$ e-P constitutes a disruptive marketing agent, the incorporation of the new system has significantly changed organisations strategy:

"We don't consider P e-P as a mere working tool. P e-P allows us to get to know other markets with less visibility or that we haven't still explored enough. With P e-P things become easier and more affordable" (SME9)

"We have specifically created two companies to explore other, new markets." (SME3) 
However, in the majority of SMEs surveyed, e-procurement has not caused disruptive impacts on the marketing models or commercial as these remained focused in the same core activity, preventing companies to obtain all the benefits of e-procurement:

"Our goal was never to use P e-P for marketing or advertsing. Of course, that could have been done, but in our particular case we didn't use it to promote ourselves (...) also, we have maintained exactly the same kind of activity" (SME2)

Regarding positive impacts on process transparency, the interviewees stated that $\mathrm{P}$ e-P provide a clear transparency increase in public procurement processes, as opposed to the previous contracting paper based. As stated in the literature (e.g., Croom and BrandonJones, 2007; Johnson, 2011), high traceability, audit and accessibility of all the information related to the public procedures which technology and related systems provide significantly contributed to this conclusion.

\subsubsection{Investments required for the new system compliance}

Pe-P's advent and public contracts dematerialisation led to reorganisation and investment in the technological infrastructure of these firm's commercial sectors.

First of all, consistent with the conclusions of Bof et al. (2007), due to the end of several logistical tasks a clear staff conversion emerged. There is evidence that staff which was allocated to logistical work were converted and assigned with tasks considered more productive and higher value adding (e.g., supplier networks development and segmentation, competition analysis). Regarding hardware, the interviewees generally referred the investment in qualified digital certificates and timestamp packs, technological infrastructural improvements and modern computer acquisition:
"(...) we have bought top equipments (...) the new system implied a revolution inside the company and staff was educated on how to use these new tools (...)there was a major investment in this area and a clear staff conversion." (SME2)
“(...) our people that were driving to submit bids and doing administrative work were reconverted into more value adding roles that provide more productive and useful use of their time" (SME5)

In conclusion, despite the technological investment, $\mathrm{P}$ e-P stimulated organisational adaptations which provided overall efficiency gains and more productive and efficient use of the economic factor labour. This led these SME to achieve increased activity and commercial prospecting while maintaining the same existing staff structure which, ultimately, could lead to higher sales volume and more contracts.

\subsubsection{Difficulties in Pe-P's implementation}

Consistent with the research of Tavares (2010), it was fairly unanimous that the complexity and purely legal language of the new code created great difficulties, especially in smaller and more reduced legal supported organisations. Plus, while acting as suppliers, SMEs need to be registered and operate in all platforms, which have different architectures and operating ways:

"One major difficulty is that we have to deal with several platforms, in some cases very different from each other Till now, we have presented proposals in 6 
or 7 different platforms, which requires us to have a strong ability to adapt." (SME5)

Moreover, it was also noted that digital signatures also constituted an obstacle for Pe-P's adoption due to doubts regarding their legal validity. It was suggested that different entities have different interpretations as to the validity of digital signatures and that this causes uncertainty (Tatsis et al., 2006).

\subsubsection{Improvement in electronic platforms and systems connected to $P$ e-P}

Although entities referred being satisfied with the platforms offered, it was often stated that a common system for basic operations would be a huge enabler, being the software vendors' differentiation, made through additional features. Moreover, the existing platforms still require simpler integrations with other systems (such as respondents' ERP or budgeting systems) which were also reported as other improvements to be made. Finally, it was also mentioned that a more effective communications management tool is needed, given the procedures high volume in which respondents participate and the resulting high volume of communications involved.

\subsubsection{Evaluation of the private supply chain modernisation}

The surveyed SME align in the private electronic platforms subscription for their supply chain. This subscription occurred after SME adopted the P e-P to their processes which. Thus, $\mathrm{P}$ e-P stimulated and represented additional drive for the surveyed SME to subscribe private contracting platforms, changing their relationships with their subcontractors and private providers. It was the drive for technology that brought other private companies, which are not directly related to public procedures. Therefore, the surveyed SME while adopting the new electronic system and invest resources in this advent, caused contagion effect on its subcontractors, encouraging and pulling them to the digital world. We conclude, therefore, that $\mathrm{P}$ e-P had a contagious effect on surveyed SME subcontractors supply chain.

\section{Conclusions}

$\mathrm{P}$ e-P is no longer a utopia as it is increasingly becoming a reality for many regions and member states (European Commission, 2010). It is widely documented that, in cases where $\mathrm{P}$ e-P is duly adopted and implemented, benefits arise for all stakeholders, whether public or private entities. Nevertheless, the use of the $\mathrm{P}$ e-P is far from expectations since it represents no more than 5\% of total spending on EU procurement (Costa et al., 2013). Some organisations, namely small businesses, may find some difficulties while leading with new technologies, systems and processes, and acting as suppliers in public procurement.

Following a case-based approach, our study explores the benefits and barriers of $\mathrm{P}$ e-P using evidence from Portuguese SMEs. Findings provide evidence of the eProcurement development in Portugal as well as the factors determining its adoption. Firms, and namely SMEs, are currently at their early stages of e-procurement use. The 
ones more likely to adopt it are those who perceive it beneficial, non-complex, compatible and of low risk. We conclude that technical factors (e.g., language, digital signatures, and electronic platforms) dominate P e-P barriers to SMEs, while cost related factors (e.g., transaction costs, information processing, time savings) dominate drivers. The challenge for e-procurement developers is to give evidence to non-users that their technologies do not undermine legal or privacy requirements and are not so technically complex that SMEs without sufficient ICT skills cannot use them. We have also identified a need for research on supplier incentives at a market level: in the majority of SMEs surveyed, e-procurement hasn't caused disruptive impacts on the marketing models or commercial as these remained focused in the same core activity. Findings also revealed that a common system for basic operations and a more effective communications management tool would be huge enablers. Policy makers may use this conclusion for boosting the adoption of e-procurement systems in SMEs.

The exploratory nature of this paper reflects the few existing studies in the area, which is in its academic infancy. This paper seeks to provide further insights to the debate in this area and to highlight key issues that may support $\mathrm{P}$ e-P decision-making. The results presented provide useful information about the factors affecting $\mathrm{P}$ e-P adoption within SMEs, with implications for supplier firms, internet model developers, and governmental policy makers, forecasting the 2016 full moving to P e-P. Also, this study adds to the growing body of literature by developing an experience-based research into the operational issues of e-procurement from the perspective of the public procurement suppliers, namely SMEs. Although this is an exploratory study, developed in a specific context with a single case study, it provides input to new theory development by proposing a "starting point" that future research should extend and further refine. One avenue for future research should be to investigate e-procurement failures as a way of furthering our understanding of critical factors for e-procurement performance. Additionally, more research would be needed in order to accurately assess the economic and financial cost-benefit with e-procurement adoption, as well as its ecological impact, associated with the tons of paper that is no longer used and the emissions of carbon dioxide that are no longer performed with the introduction of technology in these processes. Also, additional factors (e.g., cultural, political, business seasonality, existing relations with suppliers) that may affect e-procurement could be studied. Moreover, the limitations of data collection warrant caution in generalising these results beyond our small and convenience sample. Replication of this study with random sampling procedures and a large scale survey would clearly add weight to the reported results. Finally, the study refers to e-procurement adoption by SMEs in the construction sector in Portugal. Futures studies could study e-procurement adoption in other firms, sectors and countries.

\section{Acknowledgements}

The authors appreciate the work of the reviewers in assessing and commenting on the paper. We are also thankful to the organisations, which participated in this study and also to those executives who shared their valuable experiences with us. 


\section{References}

Aberdeen Group (2009) Global Supply Management (GSM): the 2009-2010 Aberdeen Agenda, [online] http://www.aberdeen.com (accessed 21 June 2012).

Adebiyi, A., Charles, A. and Adebiyi, M. (2010) 'Development of electronic government procurement (e-GP) system for Nigeria public sector', International Journal of Electrical \& Computer Sciences, Vol. 10, No. 6. pp.74-84.

Arasa, R. and Achuora, J. (2012) 'Antecedents to successful adoption of e-procurement in textile and apparel firms in Kenya', International Journal of Scientific and Engineering Research, Vol. 3, No. 10, pp.1-9.

Aslani, M.P., Laios, L.G. and Moschuris, S.J. (2008) 'The perceived impact of e-procurement in EU enterprises', International Journal of Value Chain Management, Vol. 2, No. 2, pp.168-187.

Azadegan, A. and Ashenbaum, B. (2009) 'E-procurement in services: the lagging application of innovation', International Journal of Procurement Management, Vol. 2, No. 1, pp.25-40.

Barua A., Konan, P. and Whinston, A.B. (2001) 'SME e-readiness in Malaysia: implications for planning and implementation', Journal Management Information, Vol. 10, No. 4, pp.177-181.

Basheka, B. and Sabiiti, C. (2011) 'Compliance to public procurement reforms in developing countries: the contextual perspective from Uganda', International Journal of Procurement Management, Vol. 4, No. 5, pp.535-548.

Basheka, B., Oluka, P. and Mugurusi, G. (2012) 'Adopting new approaches for public procurement efficiency: critical success factors (CSFs) for the implementation of e-procurement in Uganda's public sector', International Journal of Procurement Management, Vol. 5, No. 6, pp.712-732.

Bechtel, C. and Jayaram, J. (1997) 'Supply chain management: a strategic perspective', The International Journal of Logistics Management, Vol. 8, No. 1, pp.15-34.

Bof, F. and Previtali, P. (2007) 'Organisational pre-conditions for e-procurement in governments: the Italian experience in the public health care sector', The Electronic Journal of e-Government, Vol. 5, No. 1, pp.1-10.

Brandon-Jones, A. and Carey, S. (2011) 'The impact of user-perceived e-procurement quality on system and contract compliance', International Journal of Operations \& Production Management, Vol. 31, No. 3, pp.274-296.

Carson, D., Gilmore, A., Perry, C. and Gronhaug, K. (2001) Qualitative Marketing Research, Sage Publications, London.

Ciciriello, C. (2010) 'e-Procurement: the real benefits for SMEs', in 5th International PEPPOL Conference, Troyes, 8 November 2010.

Clark III, M. and Moutray, C. (2004) 'The future of small businesses in the US federal government market place', Journal of Public Procurement, Vol. 4, No. 3, pp.450-470.

Costa, A., Arantes, A. and Tavares, L. (2013) 'Evidence of the impacts of public e-procurement: the Portuguese experience', Journal of Purchasing and Supply Management, Vol. 19, No. 4, pp.238-246.

Croom, S. (2000) 'The impact of web-based procurement on the management of operating resources supply', The Journal of Supply Chain Management, Vol. 36, No. 1, pp.4-13.

Croom, S. and Brandon-Jones, A. (2007) 'Impact of e-procurement: experiences from implementation in the UK public sector', Journal of Purchasing and Supply Management, Vol. 13, No. 4, pp.294-303.

Croom, S. and Johnston, R. (2003) 'E-service: enhancing internal customer service through e-procurement', International Journal of Service Industry Management, Vol. 14, No. 5, pp.539-555. 
Davila, A., Gupta, M. and Palmer, R. (2003) 'Moving procurement systems to the internet: the adoption and the use of e-procurement technology model', European Management Journal, Vol. 21, No. 1, pp.11-23.

De Boer, L., Harink, J. and Heijboer, G. (2002) 'A conceptual model for assessing the impact of electronic procurement', European Journal of Purchasing and Supply Management, Vol. 8, No. 1, pp.25-33.

Doern, R. (2009) 'Investigating barriers to SME growth and development in transition environments: a critique and suggestions for developing the methodology', International Small Business Journal, Vol. 27, No. 3, pp.275-305.

Dubois, A. and Araujo, L. (2007) 'Case research in purchasing and supply management opportunities and challenges', Journal of Purchasing and Supply Management, Vol. 13, No. 3 , pp.170-181.

Eadie, R., Millar, P., Perera, S., Heaney, G. and Barton, G. (2012) 'E-readiness of construction contract forms and e-tendering software', International Journal of Procurement Management, Vol. 5, No. 1, pp.1-26.

Eei, K.S., Husain, W. and Mustaffa, N. (2012) 'Survey on benefits and barriers of e-procurement: Malaysian SMEs perspective', International Journal on Advanced Science Engineering Information Technology, Vol. 12, No. 6, pp.14-19.

European Commission (2004) Action Plan for the Implementation of the Legal Framework for Electronic Public Procurement, Brussels, 29 December 2004 [online] http://ec.europa.eu/internal_market/publicprocurement (accessed 22 April 2012).

European Commission (2010) Livro Verde relativo ao alargamento da utilização da contratação pública electrónica na UE [online] http://eur-lex.europa.eu/LexUriServ (accessed 19 June 2012).

European Commission (2011a) EU Public Procurement Legislation: Delivering Results. A Summary of Evaluation Report, p.13 [online] http://ec.europa.eu/internal_market/p publicprocurement (accessed 21 June 2012).

European Commission (2011b) Procurement as a Part of Government Expenditure [online] http://cordis.europa.eu/fp7/ict/pcp/key_en.html (accessed 21 June 2012).

Fee R, Erridge, A. and Hennigan, S. (2002) 'SMEs and government purchasing in Northern Ireland: problems and opportunities', European Business Review, Vol. 14, No. 5, pp.326-334.

Fleming, E., Kuo, C. and White, R. (2010) 'Funding e-procurement initiatives in US Government agencies: challenges, models, and trends', International Journal of Procurement Management, Vol. 3, No. 3, pp.231-244.

George, B., Williams, A. and Henthorne, T. (2011) 'E-procurement in the hospitality industry: an exploratory study', International Journal of Procurement Management, Vol. 4, No. 1, pp.37-55.

Gunasekaran, A. and Ngai, E. (2008) 'Adoption of e-procurement in Hong Kong: an empirical research', International Journal of Production Economic, Vol. 113, No. 1, pp.159-175.

Gupta, M. and Narain, R. (2012) 'Investigation into barriers to adoption of e-procurement and measures of performance', International Journal of Procurement Management, Vol. 5, No. 5, pp.567-607.

Gupta, S., Jha, B. and Gupta, H. (2011) 'Internet use and benefits in procurement for IT industry in Indian sub continent: a descriptive and conclusive analysis', International Journal of Procurement Management, Vol. 4, No. 4, pp.341-362.

Hawking, P., Stein, A., Wyld, D. and Foster, S. (2004) 'E-Procurement: is the ugly duckling actually a swan down under?', Asia Pacific Journal of Marketing and Logistics, Vol. 1, No. 1, pp.3-27.

Henriksen, H.Z. and Mahnke, V. (2005) "E-Procurement adoption in the Danish public sector: the influence of economic and political rationality', Scandinavian Journal of Information Systems, Vol. 17, No. 2, pp.85-106. 
Ho, C.F. and, Wu, W.H. (2006) 'An e-procurement impact model based on supply chain orientation: an empirical investigation', in Proceedings of the Fourth Workshop on Knowledge Economy and Electronic Commerce.

Johnson, M. (2011) 'Public sector e-procurement: a study of benefits from e-markets in the local government sector', International Journal of Services Technology and Management, Vol. 16, No. 1, pp.1-27.

Kaliannan, M., Awang, H. and Raman, M. (2009) 'Electronic procurement: a case study of Malaysia's e-perolehan (e-procurement) initiative', International Journal of Electronic Governance, Vol. 2, Nos. 2-3, pp.103-117.

Karjalainen, K. and Kemppainen, K. (2008) 'The involvement of small- and medium-sized enterprises in public procurement: impact of resource perceptions, electronic systems and enterprise size', Journal of Purchasing and Supply Management, Vol. 19, No. 4, pp.238-246.

Karthik, V. and Kumar, S. (2013) 'Investigating 'degree of adoption' effects on e-procurement benefits', International Journal of Procurement Management, Vol. 6, No. 2, pp.211-232.

Kierkegaard, S. (2006) 'Going, going, gone! E-procurement in the EU', International Journal of Computing and Information Sciences, Vol. 14, No. 4, pp.230-240.

LaLonde, B.J. (1998) 'Supply chain evolution by the numbers', Supply Chain Management Review, Vol. 2, No. 1, pp.7-8.

Lancioni, R., Smith, M. and Schau, H. (2003) 'Strategic internet application trends in supply chain management', Industrial Marketing Management, Vol. 32, No. 3, pp.211-217.

MacManus, S.A. (2002) 'Understanding the incremental nature of e-procurement implementation at the state and local levels', Journal of Public Procurement, Vol. 2, No. 1, pp.5-28.

Makinen, J., Kahkonen, A. and Lintukangas, K. (2011) 'E-procurement as a success factor in cooperative purchasing', International Journal of Procurement Management, Vol. 4, No. 1, pp.56-70.

McConnell, D.J.A. (2009) An Analysis Into the Factors Affecting the Uptake of Applications of eProcurement, Within the UK Public Sector, PhD Thesis, Loughborough University, UK.

McCue, C. and Roman, A. (2012) 'e-Procurement: myth or reality?', Journal of Public Procurement, Vol. 5, No. 1, pp.54-72.

Min, H. and Galle, W. (2003) 'E-purchasing: profiles of adopters and non-adopters', Industrial Marketing Management, Vol. 32, No. 3, pp.227-233.

Moon, M. (2005) 'e-Procurement management in state governments: diffusion of e-procurement practices and its determinants', Journal of Public Procurement, Vol. 12, No. 2, pp.212-238.

Mota, F. and Filho, J. (2011) 'Public e-procurement and the duality of technology: a comparative study in the context of Brazil and Paraíba', Journal of Information Systems and Technology Management, Vol. 8, No. 2, pp.315-330.

National Statistics Institute (2011) Estudos sobre Estatisticas Estruturais das Empresas, 2007-2009, 30 June.

Neef, D. (2001) E-procurement: From Strategy to Implementation, Prentice-Hall/Financial Times, Add Upper Saddle River, NJ.

OECD (2000) The Bologna Charter on SME Economies. Global Forum: Knowledge Economy Digital Economy [online] http://www.oecd.org/document/56/0,2340,en_2649_34619_1866232 _1_1_1_1,00.html (accessed 21 June 2012).

Office of Government Commerce (2008) Introduction to the EU Procurement Rules: OGC Guidance [online] http://webarchive.nationalarchives.gov.uk/ (accessed 19 June 2012).

Olsen, R.F. and Ellram, L.M. (1997) 'A portfolio approach to supplier relationships', Industrial Marketing Management, Vol. 26, No. 2, pp.101-113.

Oyegoke, A., McDermott, P. and Dickinson, M. (2010) 'The myth behind integration in the UK construction industry', International Journal of Procurement Management, Vol. 3, No. 2, pp.247-264. 
Panayiotou, N., Gayialis, S. and Tatsiopoulos, I. (2004) 'An e-procurement system for governmental purchasing', International Journal of Production Economics, Vol. 90, No. 1, pp.79-102.

Presutti, W. (2003) 'Supply management and e-procurement: creating value added in the supply chain’, Industrial Marketing Management, Vol. 32, No.3, pp.219-226.

Puschmann, T. and Alt, R. (2005) 'Successful use of e-procurement in supply chains', International Journal of Supply Chain Management, Vol. 10, No. 2, pp.122-133.

Rankin, J.H., Chen, Y. and Christian, A.J. (2006) 'e-Procurement in the Atlantic Canadian AEC industry', ITcon Special Issue e-Commerce in Construction, Vol. 11, pp.75-87 [online] http://www.itcon.org/2006/6.

Roberts, J.S. (2001) 'Great expectations: e-procurement and work processes', Purchasing Today, Vol. 12, No. 10, pp.24-30.

Ronchi, S., Brun, A., Golini, R. and Fan, X. (2010) 'What is the value of an IT e-procurement system?', Journal of Purchasing and Supply Management, Vol. 16, No. 2, pp.131-140.

Schiele, J. (2007) 'The role of public purchasing departments in acquisition process for consulting services', International Journal of Procurement Management, Vol. 1, Nos. 1/2, pp.144-165.

Schoenherr, T. and Tummala, V. (2007) 'Electronic procurement: a structured literature review and directions for future research', International Journal of Procurement Management, Vol. 1, Nos. $1 / 2$, pp. $8-37$.

Sigala, M. (2006) 'e-Procurement diffusion in the supply chain of foodservice operators: an exploratory study in Greece', Information Technology and Tourism, Vol. 8, No. 2, pp.79-90.

Smart, A. and Harrison, A. (2003) 'Online reverse auctions and their role in buyer-supplier relationships', Journal of Purchasing \& Supply Management, Vol. 9, Nos. 5/6, pp.257-268.

Somasundaram, R. and Damsgaard, J. (2005) 'Policy recommendations for electronic public procurement', The Electronic Journal of e-Government, Vol. 3, No. 3, pp.147-156.

Tatsis, V., Mena, C., Van Wassenhove, L. and Whicker, L. (2006) 'E-procurement in the Greek food and drink industry - drivers and impediments', Journal of Purchasing and Supply Management, Vol. 12, No. 2, pp.63-74.

Tavares, L.V. (2010) Public eTendering in the European Union - Trust in eVolution. European Vortal Academy, Lisbon.

Thai, K.V. (2001) 'Public procurement re-examined', Journal of Public Procurement, Vol. 1, No. 1, pp.9-50.

Tonkin, C. (2003) e-Procurement in the Public Sector: Story, Myth and Legend, The Policy Institute, Trinity College, Dublin.

Vaidya, K. (2007) Electronic Procurement in the Australian Public Sector: The Organizational Assimilation Process and its Impact on Public Procurement, University of New England.

Vaidya, K. and Hyde, M. (2011) 'Inter-organisational information systems assimilation: an empirical evaluation in light of the diffusion of innovation theory', International Journal of Business Information Systems, Vol. 7, No. 3, pp.247-268.

Vaidya, K., Sajeev, A. and Callender, G. (2006) 'Critical factors that influence e-procurement implementation success in the public sector', Journal of Public Procurement, Vol. 6, Nos. 1/3, pp.70-99.

Varney, M. (2011) 'E-procurement - current law and future challenges', ERA-Forum, Vol. 12, No. 2, pp.185-204.

Wen, W. and Wei, L. (2007) 'Decision-making analysis of e-procurement with the rough set theory', in International Conference on Wireless Communications, Networking and Mobile Computing, Shanghai, 21-25 September.

Yen, B. and Ng, E. (2003) 'The impact of electronic commerce on procurement', Journal of Organizational Computing and Electronic Commerce, Vol. 13, Nos. 3/4, pp.167-189.

Yin, R.K. (2014) Case Study Research: Design and Methods, Sage Publications, Thousand Oaks, CA. 
Yu, Y., Yu, H., Itoga, H. and Lin, T. (2008) 'Decision-making factors for effective industrial e-procurement', Technology in Society, Vol. 30, No. 2, pp.163-169.

Zheng, J., Caldwell, N.D., Harland, C.M., Powell, P., Woerndl, M. and Xu, S. (2004) 'Small firms and e-business: cautiousness, contingency and cost benefits', Journal of Purchasing and Supply Management, Vol. 1, No. 1, pp.27-39.

Zheng, J., Walker, H. and Harland, C. (2006) 'The role of SMEs in public procurement: a review of literature and research agenda', in 15th Annual IPSERA Conference, "Creating and managing value in supply networks", San Diego, USA. 